\title{
Patient interest in and familiarity with anti-aging therapies: A survey of the general dermatology clinic population
}

\author{
Allison M Darland $M^{1,2}{ }^{\mathbb{D}} \mid$ Heather A Chubb $\mathrm{MS}^{2} \mid$ Dana L Sachs $\mathrm{MD}^{2} \mid$ \\ Yolanda R Helfrich MD $^{2}$
}

${ }^{1}$ University of Michigan Medical School, Ann Arbor, MI, USA

${ }^{2}$ Department of Dermatology, University of Michigan Health System, Ann Arbor, MI, USA

Correspondence

Allison M Darland, Department of Dermatology, University of Michigan Health System, Ann Arbor, MI, USA.

Email: darlanda@umich.edu

\begin{abstract}
Summary
Background: The appearance of aging skin is a common complaint among dermatology patients. There is an expanding market for anti-aging therapies, but little information is available regarding which patients utilize these treatments and patient preferences regarding treatment.

Aims: To describe the patient population utilizing anti-aging therapies, assess patient familiarity with treatment options, and learn where treatment information is most often obtained.

Patients/Methods: Three hundred patients were surveyed in the University of Michigan General Dermatology Clinic.

Results: Fifty-three percent of the general dermatology patient population has used an anti-aging treatment in the past; $66 \%$ reported interest in the future use. Interest is high among all genders, ages, and incomes. Most subjects obtained treatment information from magazines, but subjects were more likely to pursue treatment if information was obtained from a dermatologist.

Conclusion: Demographics of anti-aging therapy are changing, and a wide variety of patients pursue treatment. Patients are largely unfamiliar with most treatment options and are more likely to pursue treatment after receiving treatment information from a dermatologist. The information presented in this study is helpful to both dermatologists and marketers of anti-aging products.
\end{abstract}

\section{KEYWORDS}

anti-aging, cosmeceuticals, patient interest, patient knowledge, survey

\section{1 | INTRODUCTION}

The appearance of aging skin is a common complaint among general dermatology clinic patients. Therapies currently available for the treatment of aging skin are numerous and include sun protection, topical therapies, systemic treatments, neurotoxin injections, soft-tissue fillers, chemical peels, laser treatments, and surgery. ${ }^{1-7}$

There has been a drastic increase in the demand for anti-aging products and procedures in recent years. ${ }^{8-11}$ The use of cosmeceuticals, non-FDA regulated cosmetic products with drug-like, but not biologic, therapeutic benefits, ${ }^{1,2,12}$ has shown a particularly rapid increase. The United States is currently the largest market for cosmeceuticals in the world, with sales exceeding $\$ 5$ billion in $2007^{8}$ and increasing to $\$ 9.7$ billion in $2011 .^{9}$ The total global market for all anti-aging therapies has been projected to be an impressive $\$ 216.52$ billion in $2021 .^{13}$

Despite the fast growing market for anti-aging therapies, surprisingly little research has been carried out to describe specific patient groups that are most interested in utilizing these therapies. Generally, women and older individuals are thought to be the primary users; however, new market research shows that this is changing. ${ }^{8}$ And while little research has been performed to show who is using 
these products, even less research has been carried out to assess patient familiarity with different therapies and where patients are most likely to obtain treatment information.

As use of anti-aging therapies continues to expand, it will become increasingly important to understand which patient groups are interested in pursuing anti-aging skin treatments. In addition to looking at treatment use in our patient population, we assessed the level of intervention that patients are taking in order to reverse the signs of aging skin. Rather than asking about specific treatments, we inquired about treatment use in broad, general categories including sun protection, creams and lotions (topicals), oral supplements, neurotoxin injections, soft-tissue fillers, chemical peels, laser treatments, and cosmetic surgery. This allows us to evaluate what method of therapy patients is most likely to pursue whether it be primary prevention with sunscreen, damage reversal with a daily skin care routine, or more involved and expensive interventions with peels, injections, or surgery. In a sense, this allows us to see how aggressively patients are willing to pursue younger looking skin.

\section{2 | MATERIALS AND METHODS}

\section{1 | Targeted population and survey methodology}

Three hundred subjects, aged 18 or older, were recruited at the University of Michigan General Dermatology Clinic. Patients were approached in person by the survey author and asked to complete the survey document. Patients who declined to participate were not included in our data set. The survey period ended upon achieving our goal of 300 completed patient surveys. University of Michigan Institutional Review Board approval was obtained (HUM00077172, June 3 , 2013) prior to administration of the survey.

\subsection{Survey}

Our survey (Data S1) consisted of 25 questions on anti-aging treatment use (sun protection, topicals, systemic treatments, injections, fillers, chemical peels, laser treatments, and surgery). Subjects answered questions about past, present, and future use of specific anti-aging treatment options and qualified their level of future interest in treatment options as "very," "moderately," "mildly," or "not at all" interested.

Additionally, subjects described their familiarity with treatment options as "very," "moderately," "mildly," or "not at all" familiar and identified sources of treatment information. Subjects reported barriers to treatment (cost, complications, short duration of effect, interference with "natural aging," belief that treatments are not needed, and stigma), reporting how significantly they play a role in preventing use.

Finally, a variety of demographic information was collected in addition to information on sunscreen use, diet, and exercise habits.

\section{3 | Statistical analysis}

Descriptive statistics were calculated to summarize the survey population. Analyses were performed using SAS version 9.3 (SAS Institute
Inc, Cary, NC, USA). Correlations with r-values of $>.2$ were considered significant when $P$-values were $<.0001$.

\section{RESULTS}

Patient demographics are summarized in Table 1.

\subsection{Past, current, and future use of anti-aging therapies}

Over half of subjects reported using anti-aging therapies at some point in the past (53\%). This includes the use of sun protection when used at least in part to prevent premature skin aging (in addition to other goals such as avoiding a painful sunburn). Women were more likely to have utilized treatments in the past $(r=.30,<.0001)$ with $65 \%$ of women and $35 \%$ of men reporting past use (Table 2). Most commonly used therapies included sun protection (51\%) and topical therapies (33\%) while very few subjects reported a history of using other treatments (3\% or less for all other options; Table 3). Slightly less than half $(48 \%)$ of the survey population were currently using treatments, with past users being more likely to also be current users $(r=.84,<.0001)$.

Most subjects (66\%) were interested in the future use of antiaging therapies, again with sun protection and topical treatments being most popular (52\% and $37 \%$ describing themselves as "very interested" in use, respectively). Other treatment modalities were much less popular among future users (7\% or less as "very interested" for all remaining options). Women were more likely than men to be interested (75\% vs $51 \% ; r=.25,<.0001$; Table 2 ). Both past and current users were more likely to have interest in the future use ( $r=.57,<.0001$ and $r=.58,<.0001$, respectively).

While the largest proportion of subjects aged $41-50$ and $61-70$ reported using anti-aging treatments in the past $(58 \%$ of both groups), there was no statistically significant difference in treatment history between any age groups. Additionally, there is no significant difference in interest in the future use among age groups. Past use appeared to be highest among those reporting a household income of $\$ 150000$ to $\$ 200000$ per year $(68 \%)$ and least among those making less than $\$ 15000$ per year (30\%). The highest level of interest in the future use was reported by those making $\$ 15000$ to $\$ 24999$ per year (80\%; Table 2). No significant difference was found between income brackets regarding past use and interest in the future use.

\section{2 | Patient familiarity with current treatment options}

Sun protection (using either sunscreen, protective clothing, or sun avoidance) was overwhelmingly the therapy which subjects had the most familiarity. Seventy percent of subjects reported being "very familiar" with sun protection use specifically as an anti-aging therapy versus only $9 \%$ who reported that they are "not at all familiar" with 
TABLE 1 Patient demographics

\begin{tabular}{|c|c|c|}
\hline & $\mathrm{n}$ & $\%$ \\
\hline \multicolumn{3}{|l|}{ Gender } \\
\hline Male & 121 & 40 \\
\hline Female & 179 & 60 \\
\hline \multicolumn{3}{|l|}{ Age } \\
\hline $18-30$ & 52 & 17 \\
\hline $31-40$ & 37 & 12 \\
\hline $41-50$ & 48 & 16 \\
\hline $51-60$ & 54 & 18 \\
\hline $61-70$ & 58 & 20 \\
\hline$>70$ & 51 & 17 \\
\hline \multicolumn{3}{|l|}{ Race } \\
\hline African American & 23 & 8 \\
\hline American Indian/Alaskan & 1 & 1 \\
\hline Caucasian & 253 & 85 \\
\hline East Asian & 3 & 1 \\
\hline Latino/Hispanic & 4 & 1 \\
\hline Mediterranean & 4 & 1 \\
\hline Southeast Asian/Indian & 8 & 2 \\
\hline Other & 2 & 1 \\
\hline \multicolumn{3}{|l|}{ Skin type } \\
\hline Type I & 47 & 16 \\
\hline Type II & 129 & 43 \\
\hline Type III & 86 & 29 \\
\hline Type IV & 26 & 9 \\
\hline Type V & 7 & 2 \\
\hline Type VI & 3 & 1 \\
\hline \multicolumn{3}{|l|}{ Education } \\
\hline$<$ High school degree & 5 & 1 \\
\hline High school/GED & 30 & 10 \\
\hline Some college & 59 & 20 \\
\hline Associate's degree & 23 & 8 \\
\hline Bachelor's degree & 80 & 27 \\
\hline Master's degree & 62 & 21 \\
\hline Doctorate degree & 39 & 13 \\
\hline \multicolumn{3}{|l|}{ Income } \\
\hline$<\$ 15000$ & 23 & 9 \\
\hline$\$ 15000$ to $\$ 24999$ & 10 & 4 \\
\hline$\$ 25000$ to $\$ 49999$ & 44 & 16 \\
\hline$\$ 50000$ to $\$ 74999$ & 50 & 19 \\
\hline$\$ 75000$ to $\$ 99999$ & 34 & 13 \\
\hline$\$ 100000$ to $\$ 149999$ & 47 & 18 \\
\hline$\$ 150000$ to $\$ 200000$ & 31 & 12 \\
\hline$>\$ 200000$ & 24 & 9 \\
\hline
\end{tabular}

this option. Thirty percent of subjects reported being "very familiar" with topical therapies, but appeared to be much less familiar with other therapies such as neurotoxin injections, soft-tissue fillers,
TABLE 2 Past, current, and future treatment use

\begin{tabular}{|c|c|c|c|c|c|}
\hline & \multicolumn{3}{|c|}{$\mathrm{n}$} & & $\%$ \\
\hline \multicolumn{6}{|l|}{ Past use (sunscreen included) } \\
\hline \multicolumn{2}{|l|}{ Yes } & \multicolumn{2}{|c|}{158} & & 53 \\
\hline \multicolumn{2}{|l|}{ No } & \multicolumn{2}{|c|}{142} & & 47 \\
\hline \multicolumn{6}{|c|}{ Past use (sunscreen not included) } \\
\hline \multicolumn{2}{|l|}{ Yes } & \multicolumn{2}{|c|}{102} & & 34 \\
\hline \multicolumn{2}{|l|}{ No } & \multicolumn{2}{|c|}{198} & & 66 \\
\hline \multicolumn{6}{|l|}{ Past treatment options } \\
\hline \multicolumn{2}{|l|}{ Sun protection } & \multicolumn{2}{|c|}{154} & & 51 \\
\hline \multicolumn{2}{|l|}{ Creams/lotions } & \multicolumn{2}{|c|}{99} & & 33 \\
\hline \multicolumn{2}{|l|}{ Oral meds/supplements } & \multicolumn{2}{|c|}{5} & & 2 \\
\hline \multicolumn{2}{|l|}{ Injections } & \multicolumn{2}{|c|}{6} & & 2 \\
\hline \multicolumn{2}{|l|}{ Fillers } & \multicolumn{2}{|c|}{4} & & 1 \\
\hline \multicolumn{2}{|l|}{ Chemical peels } & \multicolumn{2}{|c|}{10} & & 3 \\
\hline \multicolumn{2}{|l|}{ Laser treatments } & \multicolumn{2}{|c|}{5} & & 2 \\
\hline \multicolumn{2}{|l|}{ Surgery } & & 2 & & 1 \\
\hline Current use (sunscreen incl & led) & & & & \\
\hline Yes & & & & & 48 \\
\hline No & & & & & 52 \\
\hline Current use (sunscreen not & cluded & & & & \\
\hline Yes & & & 0 & & 30 \\
\hline No & & & & & 70 \\
\hline Interest in the future use (s & sscreen & cluded & & & \\
\hline Yes & & & & & 66 \\
\hline No & & & & & 34 \\
\hline Interest in the future use & iscreen & ot incle & & & \\
\hline Yes & & & & & 57 \\
\hline No & & & & & 43 \\
\hline & Very & Mod. & Mild & Not at all ( & \\
\hline Future treatment options & & & & & \\
\hline Sun protection & 52 & 8 & 2 & 38 & \\
\hline Creams/lotions & 37 & 10 & 5 & 48 & \\
\hline Oral meds/supplements & 7 & 6 & 8 & 79 & \\
\hline Injections & 5 & 3 & 5 & 87 & \\
\hline Fillers & 6 & 3 & 5 & 86 & \\
\hline Chemical peels & 5 & 6 & 7 & 82 & \\
\hline Laser treatments & 7 & 7 & 10 & 76 & \\
\hline Surgery & 3 & 2 & 4 & 91 & \\
\hline
\end{tabular}

chemical peels, laser treatments, surgery, and systemic oral therapies (Figure 1). There was a statistically significant positive correlation between past use and familiarity with specific treatments including sun protection $(r=.34,<.0001)$, topicals $(r=.56,<.0001)$, injections $(r=.24,<.0001)$, fillers $(r=.22,<.0001)$, and chemical peels $(r=.25$, $<.0001$ ), showing that subjects who had used these treatments in the past knew more about them. No such correlation existed for oral supplements, lasers, or surgery, suggesting that even subjects utilizing these therapies did not feel as though they had adequate 
TABLE 3 Interest by gender, age, and income

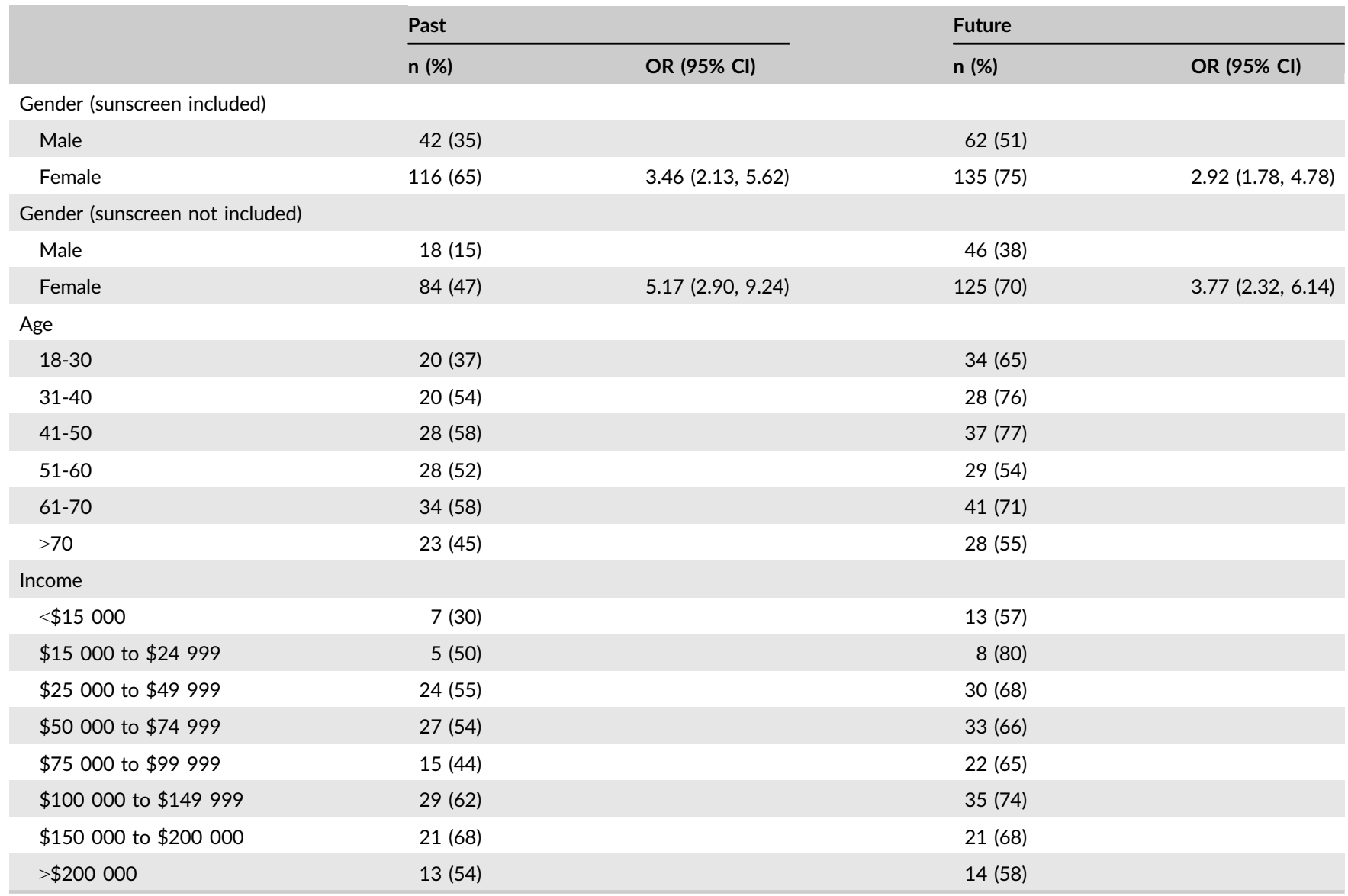

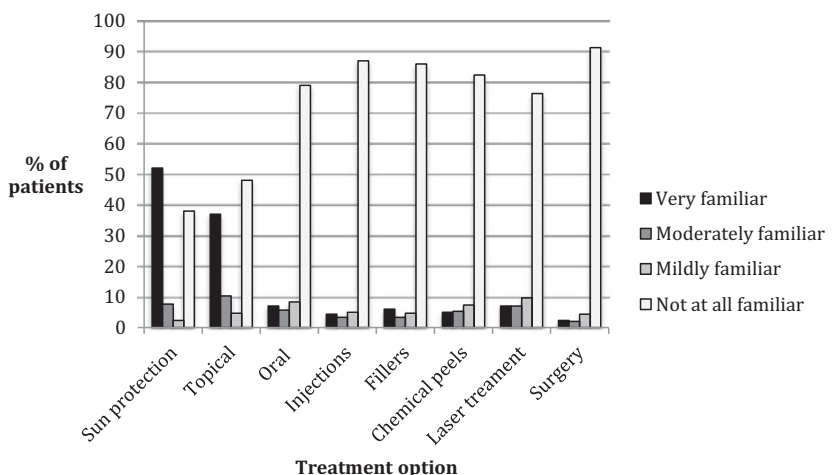

FIGURE 1 Patient familiarity with treatment options

information about them; however, it is important to note that the number of subjects with a history of using these specific treatments was quite low.

\subsection{Sources of information regarding possible treatments}

The most commonly reported source of information regarding antiaging therapies was magazines (51\%). Other common sources include television commercials (49\%), a dermatologist (40\%), and friends or family (39\%). Subjects were least likely to obtain treatment information from their primary care physician, with only $18 \%$ reporting this as a source (Table 4).

Among subjects who identified their dermatologist as a major information provider, $85 \%$ indicated interest in the future use of anti-aging therapies. A smaller proportion of subjects who identified friends and family, a primary care doctor, the Internet, magazines, and TV commercials as a major source of treatment information were also interested in seeking treatment in the future $(80 \%, 79 \%$, $74 \%, 72 \%$, and $60 \%$, respectively).

\section{4 | Barriers to treatment use}

Barriers to anti-aging therapy use were assessed. The most significant barrier reported was potential risks and complications, with $61 \%$ citing this as a "very significant" reason to avoid seeking treatment and only $13 \%$ saying this was "not at all significant" (Figure 2). Among past, present, and future users specifically, these subjects were more likely to report risks as a barrier $(r=.23,<.0001 ; r=.28$, $<.0001 ; r=.37,<.0001$ ) compared to nonusers.

Another common barrier was concern over cost, with $46 \%$ of subjects reporting this as a "very significant" factor in the decision to avoid any particular treatment. A negative correlation was observed between age and cost as a barrier $(r=-.25,<.0001)$, showing that cost is a less significant barrier as age increases. Less common 
TABLE 4 Source of information regarding anti-aging therapies

\begin{tabular}{|c|c|c|c|}
\hline & n & $\%$ & $\begin{array}{l}\% \text { interested in } \\
\text { the future use }\end{array}$ \\
\hline \multicolumn{4}{|c|}{ Source providing any treatment info } \\
\hline Primary care & 53 & 18 & \\
\hline Dermatologist & 121 & 40 & \\
\hline Friends/family & 116 & 39 & \\
\hline Magazine/newspaper & 153 & 51 & \\
\hline Internet & 102 & 34 & \\
\hline TV commercials & 147 & 49 & \\
\hline Other & 28 & 9 & \\
\hline \multicolumn{4}{|c|}{ Source providing the majority of treatment info } \\
\hline Primary care & 29 & 10 & 79 (23 of 29$)$ \\
\hline Dermatologist & 78 & 26 & 85 (66 of 78$)$ \\
\hline Friends/family & 59 & 20 & $80(47$ of 59$)$ \\
\hline Magazine/newspaper & 79 & 26 & 72 (57 of 79$)$ \\
\hline Internet & 50 & 17 & 74 (37 of 50$)$ \\
\hline TV commercials & 97 & 32 & 60 (58 of 97) \\
\hline
\end{tabular}

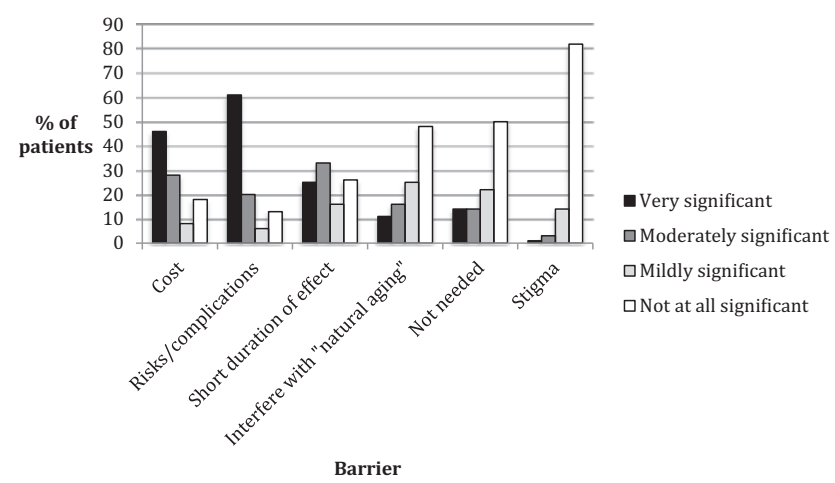

FIGURE 2 Barriers to seeking treatment

barriers to treatment include short duration of effects, believing that treatments are not needed, belief that treatment is unnatural, and stigma with only $25 \%, 14 \%, 11 \%$, and $1 \%$ of subjects rating these reasons as "very significant," respectively (Figure 2).

\subsection{Association of anti-aging therapy use with "healthy habits"}

Subjects were asked to report on healthy habits that could also be considered appearance-improving behaviors (healthy diet, exercise routine, and sunscreen use). Most subjects described their diet as "somewhat healthy" (62\%). Exercise habits were described as "occasional," "frequent," and "daily" by $35 \%, 21 \%$, and $18 \%$ of subjects, respectively (Table 5).

The majority of our patient population (31\%) reported using sunscreen only occasionally (Table 5). A negative correlation was found between skin type and sunscreen use, showing that with increasing pigmentation (Fitzpatrick skin type value), subjects were less likely to use sunscreen $(r=-.27,<.0001)$.
TABLE 5 Heath habits

\begin{tabular}{|c|c|c|c|}
\hline & $n$ & $\%$ & $\begin{array}{l}\% \text { interested in } \\
\text { the future use }\end{array}$ \\
\hline \multicolumn{4}{|l|}{ Diet } \\
\hline Very healthy & 86 & 29 & 70 \\
\hline Somewhat healthy & 187 & 62 & 65 \\
\hline Not very healthy & 24 & 8 & 54 \\
\hline Unhealthy & 2 & 1 & 100 \\
\hline \multicolumn{4}{|l|}{ Exercise } \\
\hline Daily & 55 & 18 & 75 \\
\hline 4-6 times per week & 62 & 21 & 66 \\
\hline 2-3 times per week & 105 & 35 & 64 \\
\hline 0-1 times per week & 62 & 22 & 64 \\
\hline Never & 13 & 4 & 54 \\
\hline \multicolumn{4}{|l|}{ Sunscreen use } \\
\hline Daily, year-round & 62 & 21 & 80 \\
\hline Daily, spring/summer & 36 & 12 & 83 \\
\hline Most days & 36 & 12 & 83 \\
\hline Occasionally & 94 & 31 & 56 \\
\hline Rarely & 45 & 15 & 58 \\
\hline Never & 26 & 19 & 27 \\
\hline
\end{tabular}

There was a positive correlation between past, current, and future use of anti-aging treatments and more frequent sunscreen use $(r=.47,<.0001 ; r=.49,<.0001 ; r=.31,<.0001)$. Subjects reporting sunscreen use as "daily, year-round," "daily, spring/summer only," and "frequently, most days per week" were interested in pursuing anti-aging treatments $80 \%, 83 \%$, and $83 \%$ of the time, respectively. Among those who never use sunscreen, only $27 \%$ reported interest in the future anti-aging treatments (Table 5).

Seventy-five percent of subjects who exercised daily were interested in the future use of anti-aging therapy, while only $54 \%$ of those who never exercised showed interest. Subjects who consumed a "very healthy" diet were interested in the future treatment $70 \%$ of the time, versus only $58 \%$ of combined "not very healthy" and altogether "unhealthy" eaters (Table 5). These trends suggest that healthier habits are associated with increased treatment interest, but were not found to be statistically significant.

\section{4 | DISCUSSION}

Our study demonstrates that over half of our general dermatology clinic patients have used some form of anti-aging therapy and almost two-thirds are interested in the future use. This is substantially higher than the percentages reported from surveys of the general population. A 2012 consumer survey reported that only $28 \%$ of the population is using anti-aging therapies. ${ }^{9}$ One possible explanation for this discrepancy is that interest in treatments, in both the general population and dermatology patient population, is continuing to increase as time progresses. Additionally, it is possible that 
dermatology patients may be more interested in seeking treatment compared to the general population. They may in some way be "more aware" of the appearance of their skin, as they are actively seeking treatment for skin conditions.

Women are by far the group most targeted by anti-aging product marketers, with past studies showing that women are over 10 times more likely to use anti-aging therapies than men. ${ }^{14}$ Among our population, women were only 3.46 times more likely to report previous use of anti-aging treatments $(95 \% \mathrm{Cl} 2.13,5.62)$ and only 2.92 times more likely to desire future treatment $(95 \% \mathrm{Cl} 2.13,5.62)$. This supports the assertion that men are a growing population of skin care consumers. $^{8}$

Past studies have shown that the use of anti-aging therapies increases with age, with one study reporting that 50-59 year olds are six times more likely to use some anti-aging therapy than 1829 year olds. ${ }^{14}$ The odds ratio for a similar age grouping in our study (51-60 vs $18-30$ year olds) was 1.05 , but not significant. There was no difference in use between any age groupings in our study. These data suggest that anti-aging treatments are commonly used by individuals of all ages, with no particular group being more likely to have used therapies in the past and is consistent with newer market trends showing that it is not only the older population that is seeking anti-aging skin therapy. ${ }^{13}$ Our study suggests that even those in their teens and twenties are seeking to keep skin looking young. We found that an impressive $65 \%$ of those aged 18-30 are planning to use treatments in the future and $48 \%$ are already current users.

Our data suggest that while patients with a higher annual household income may be more likely to report prior use, patients from all economic backgrounds reported interest in future use. Appearance may be something that patients are willing to spend money on, even in hard economic times.

It is not surprising that sun protection is the anti-aging therapy with which our patient group is most familiar, as this is the most commonly used treatment in this population. Subjects seem to be most familiar with treatments that are more commonly advertised on television and in magazines (shown by our survey to be the most common sources of treatment information), such as sun protection and creams, and less familiar with treatments such as surgery, neurotoxin injections, and soft-tissue fillers, which are less commonly advertised here. The treatment that subjects are least familiar with is systemic therapies. It is important to note that oral supplementation is a relatively new trend, and this potential therapy remains a controversial topic among researchers without strong evidence of effectiveness. ${ }^{15,16}$

Although doctors are reported as the most trusted source for health information, the internet remains the most commonly used first source ${ }^{17}$ and a striking $55 \%$ of American adults use the Internet for medical information. ${ }^{14}$ With this in mind, it is somewhat surprising that only $35 \%$ reported the Internet to be an anti-aging treatment information source (5th most common source).

Our study showed that $85 \%$ of subjects who cited a dermatologist as providing "a majority" of their treatment information were interested in using anti-aging treatments in the future. Subjects who cited the television commercials or magazines as a major information source were less interested in the future use. While patients may be more likely to obtain information from other sources, they may be more likely to trust information provided by a dermatologist.

The most significant barrier to seeking anti-aging treatment among subjects was concern over risks and complications, with $61 \%$ reporting this as being "very significant." In keeping with this concern, subjects were least interested in surgical therapies (only 3\% as "very interested"), which have the highest complication rates and longest posttreatment recovery period. ${ }^{4}$ Topical therapies and less invasive procedures with fewer side effects were preferable to subjects.

A 2010 study showed that cost and short duration of effect were factors in deciding to pursue treatment in $60 \%$ and $68 \%$ of women. ${ }^{18}$ Our study data suggest that cost is the second most common barrier to pursuing treatment with $46 \%$ of subjects citing cost as a "very significant" deterrent and only $18 \%$ saying that it would not impact their decision at all. Cost as a barrier was found to have a relationship with lower income $(P=.0007)$ and appears to be a greater concern to subjects making less than $\$ 15000$ per year, compared to those with higher annual income.

As anti-aging therapies aim to improve appearance, it would make sense that patients using these treatments may also participate in other appearance-improving behaviors as well; however, healthy diet and exercise habits were not significantly associated with increased treatment use or treatment interest. On the other hand, healthier sunscreen habits were associated with an increased interest in the future anti-aging treatments. Interestingly, past studies have suggested that increasing sunscreen use among patients can, in part, be attributed to the media advertising its anti-aging properties. ${ }^{19}$ Our data show that subjects with the most frequent sunscreen use are more likely to pursue anti-aging treatments. Of note, the majority of our patient population (31\%) reported using sunscreen only occasionally, consistent with previous studies suggest that less than half of the general population uses sunscreen on a regular basis. ${ }^{7}$

In conclusion, these data demonstrate that the demographics of anti-aging therapy are changing, and that a wide variety of patients are now pursuing anti-aging treatments. Most patients are largely unfamiliar with many treatment options. It is important to note that those individuals who received a majority of their treatment information from a dermatologist are more likely to pursue treatment. Therefore, it is important for dermatologists to inquire about patient interest in anti-aging therapies and to provide information about available treatment options. We believe the data presented in this study provides valuable information to dermatologists and product marketers alike.

\section{CONFLICTS OF INTEREST}

None.

\section{REFERENCES}

1. Bermann PE. Aging skin: causes, treatments, and prevention. Nurs Clin North Am. 2007;42:485-500, vii. 
2. Ganceviciene R, Liakou Al, Theodoridis A, Makrantonaki E, Zouboulis CC. Skin anti-aging strategies. Dermatoendocrinology. 2012;4:308 319.

3. Helfrich YR, Sachs DL, Voorhees JJ. Overview of skin aging and photoaging. Dermatol Nurs. 2008;20:177-183.

4. McCullough JL, Kelly KM. Prevention and treatment of skin aging. Ann N Y Acad Sci. 2006;1067:323-331.

5. Robinson DM, Aasi SZ. Cosmetic concerns and management strategies to combat aging. Maturitas. 2011;70:256-260.

6. Lupo MP. Hyaluronic acid fillers in facial rejuvenation. Semin Cutan Med Surg. 2006;25:122-126.

7. Palm MD, O'Donoghue MN. Update on photoprotection. Dermatol Ther 2007;20:360-376.

8. Stucky D, McCracken DS. The Cosmeceutical Marketplace. Draelos: Procedures in Cosmetic Dermatology - Cosmeceuticals, 2nd edn. Philadelphia: Elsevier; 2009. pp. 24-25.

9. Brown S. Cosmeceuticals in the US, 6th edn. New Orleans: Packaged Facts, Marigny Research Group; 2012.

10. Lee EH, Nehal KS, Dusza SW, Hale EK, Levine VJ. Procedural dermatology training during dermatology residency: a survey of thirdyear dermatology residents. J Am Acad Dermatol 2011;64:475-483, 483.e1-5.

11. Draelos ZD. The cosmeceuticals realm. Clin Dermatol. 2008;26:627632.

12. Choi CM, Berson DS. Cosmeceuticals. Semin Cutan Med Surg. 2006;25:163-168.

13. Zion Market Research. Anti-Aging (Baby Boomer, Generation $X$ and Generation Y) Market, by product (Botox, Anti-Wrinkle Products, Anti-Stretch Mark Products, and Others), by Services (Anti-Pigmentation Therapy, Anti-Adult Acne Therapy, Breast Augmentation, Liposuction, Chemical Peel, Hair Restoration Treatment, and Others), by Device (Microdermabrasion, Laser Aesthetics, Anti-Cellulite Treatment and Anti-Aging Radio Frequency Devices): Global Industry Perspective, Comprehensive Analysis, Size, Share, Growth, Segment, Trends and Forecast, 2015 - 2021. Zion Market Research, Sarasota,
2016 July. www.zionmarketresearch.com/toc/anti-aging-market. Accessed April 21, 2017.

14. Bhutani T, Peng D, Shin T, Lee H. Common sources of skin care education: a cross-sectional study. Int J Dermatol. 2009;48:506-512.

15. Schagen SK, Zampeli VA, Makrantonaki E, Zouboulis CC. Discovering the link between nutrition and skin aging. Dermatoendocrinology. 2012;4:298-307.

16. Draelos ZD. Nutrition and enhancing youthful-appearing skin. Clin Dermatol. 2010;28:400-408.

17. Hessen BW, Nelson DE, Kreps GL, et al. Trust and sources of health information: the impact of the internet and its implications for health care providers: findings from the first Health Information National Trends Survey. Arch Intern Med. 2005;165:2618-2624.

18. Weinkle S, Lupo M. Attitudes, awareness, and usage of medical antiaging treatments: results of a patient survey. J Clin Aesthet Dermatol. 2010;3:30-33.

19. Goulart JM, Wang SQ. Knowledge, motivation, and behavior patterns of the general public towards sun protection. Photochem Photobiol Sci. 2010;9:432-438.

\section{SUPPORTING INFORMATION}

Additional Supporting Information may be found online in the supporting information tab for this article.

How to cite this article: Darland AM, Chubb HA, Sachs DL, Helfrich YR. Patient interest in and familiarity with anti-aging therapies: A survey of the general dermatology clinic population. J Cosmet Dermatol. 2018;17:403-409. https://doi.org/10.1111/jocd.12386 